\title{
Intellectio e Inventio en la Traducción de Poesía del Turco
}

\section{Intellectio and Inventio in Turkish Poetry Translation}

\author{
Rafael CARPINTERO 1 (1)
}

'Prof. Dr., Istanbul University, Faculty of Letters, Department of Spanish Language and Literature, Istanbul, Turkey

ORCID: R.C. 0000-0003-2790-5160

\section{Corresponding author:}

Rafael CARPINTERO,

Istanbul University, Faculty of Letters, Department of Spanish Language and Literature, Istanbul, Turkey

E-mail: ortega@istanbul.edu.tr

Submitted: 05.06.2020

Accepted: 29.09 .2020

Citation: Carpintero, R. (2020). Intellectio and inventio in Turkish poetry translation. Litera, 30(2), 579-601.

https://doi.org/10.26650/LITERA2020-0083

\begin{abstract}
RESUMEN
La neorretórica ha vuelto a tomar el sentido clásico de la retórica como ciencia del discurso y no únicamente como estudio de las figuras. Las aportaciones de la lingüística contemporánea, en particular de la pragmática, al análisis del discurso como lengua en acción demuestran la validez de los postulados de la retórica clásica. En ese sentido es perfectamente posible aplicar categorías de la retórica al análisis de la traducción puesto que se trata una actividad comunicativa que emplea la lengua como medio de transmisión. Sin embargo, conviene superar la tradicional dedicación al nivel más superficial de la elocutio y prestar atención a otros, bien previos al discurso, como la intellectio, o formantes de él, como la inventio. Podemos considerar la intellectio como la localización del autor previa al texto tanto desde el punto de vista del campo como del modo y el tenor. En cuanto a la inventio, es una enciclopedia de temas y formas de tratarlos condicionada cultural e históricamente. La traducción de un texto puede encontrar problemas en ambos niveles que van más allá de los estrictamente léxicos, aunque acaben siendo reflejados en palabras. Como ejemplo utilizamos las traducciones al español, a través de una lengua intermedia, de dos poemas de Ataol Behramoğlu originalmente en turco.
\end{abstract}

Palabras Clave: Neorretórica, inventio, intellectio, traducción, Ataol Behramoğlu

\section{ABSTRACT}

New Rhetorics has returned to the classical meaning of rhetoric as a science of discourse and not only as a study of literary figures. The contributions of contemporary linguistics, particularly pragmatics, to the analysis of discourse as «language in action» demonstrate the validity of the postulates of classical rhetoric. In this sense, it is perfectly possible to apply categories of rhetoric to the analysis of translation since it is a communicative activity that uses language as a means of transmission. However, it is convenient to overcome the traditional dedication at the most superficial level of elocutio and pay attention to other levels, be it before the performance of the discourse, such as intellectio, or being formants of it, such as inventio. We can consider the intellectio as the location of the author prior to the text from the point of view of field, mode and tenor. Inventio is an encyclopedia of topics and ways of treating them conditioned culturally and historically. The translation of a text can find problems at both levels that go beyond those strictly lexical, even if they end up being reflected in words. As an example, we use the translations into Spanish, with an intermediate language, of two poems by Ataol Behramoğlu originally in Turkish.

Keywords: New rhetorics, intellectio, inventio, translation, Ataol Behramoğlu 


\section{EXTENDED ABSTRACT}

Since the mid- $20^{\text {th }}$ century, rhetoric has experienced a relative renaissance. From the Middle Ages until recently, rhetoric had been seen above all as the study of the figures used in literature, therefore called rhetorical figures. However, that was only one part of the classical rhetoric, which was actually the science of discourse, of oral expression, of speech.

It is in the same meaning of science of discourse that it has begun to be considered again with the beginning of neo-rhetoric studies. The development of linguistics has undoubtedly contributed to this, giving greater importance to speech/parole after structuralism, and, above all, to the appearance of pragmatics in linguistic studies, with its insistence on the theory of acts of speech and on discourse as a communicative fact.

Since translation is a communicative act that uses linguistic means, it should deserve the attention of neo-rhetorical studies and vice versa. However, there are very few studies of rhetoric dealing with translation and hardly any studies on translation using categories of classical rhetoric. The truth is that the so-called "translation techniques" can be reduced to the four basic operations of classical rhetoric (addition, subtraction, transposition and permutation) at linguistic as well as discursive and pragmatic levels. These operations usually refer to a single part of those that formed the art of rhetoric: elocutio, the form of expression. However, there are other levels at which deeper translation problems can arise: the intellectio and the inventio.

The intellectio is an operation prior to the generation of the discourse and, in brief, consists of the correct appreciation from a pragmatic point of view of the context - both referential and textual - by the addresser. Thus, before producing the text, the author must be fully aware of questions such as to whom it is addressed, what the situation is, the means of communication, or the conventions of the textual types of the subject being handled.

Classical inventio was a repertoire of themes and subtopics, as well as how to develop them. For example, if you wanted to talk about the passage of time, you could use themes such as tempus fugit or carpe diem. In the latter there should always be a poetic voice - presumably an adult man - addressing a young woman, the poem should begin 
with a description of this young woman - descriptio puellae - who must be blonde and of pale and delicate skin, etc.

Taking into account that the translator is a professional reader of the original text and also the producer of the translated text, it is evident that he must pay careful attention not only to the position taken by the original author - his/her «location» -, but also to his own. In other words, you have to carefully analyze the level of the intellectio before undertaking the translation in order to detect possible problems. The same is true for the level of inventio since not all subjects are treated in the same way in all cultures or at all times.

As an example of the problems that can arise both at the level of the intellectio and the inventio, we propose the translation into Spanish from a French or English version of two poems by the Turkish author Ataol Behramoğlu. In the first we can see problems in the approach to the feminine as a theme, a question clearly related to inventio. In the second, a difference, already visible in the English translation, appears in the previous position of the author and the translators, difference that would correspond to the level of the intellectio.

In sum, the categories that classical rhetoric offers us are perfectly applicable to translation analysis and need not to be limited to elocutio or rhetorical figures, but may include more "abstract" aspects dealt with by intellectio or inventio. 


\section{La neorretórica como ciencia del discurso}

A mediados del siglo pasado, se produjo un resurgimiento del interés por la retórica, especialmente a partir de los estudios de Chaim Perelman - su Tratado de la argumentación. La nueva retórica es de 1958 - y de Heinrich Lausberg - que publicó sus Elementos de retórica literaria en 1949 y el Manual de retórica literaria en 1960 -. Mientras que Perelman se orientaba más directamente hacia la oratoria y la filosofía, Lausberg lo hacía hacia la literatura (García Berrio, 1984, pág. 7). Sin embargo, ambos apostaban decididamente por una comprensión de la retórica como una disciplina general del discurso, como, de hecho, había sido en la Antigüedad (García Berrio, 1984, pág. 17).

Tanto en la Grecia como en la Roma clásicas, culturas fuertemente orales, la retórica era el estudio de la expresión de la forma más eficiente posible o «bien decir» - ars bene dicendi - frente a la gramática, que era el arte de «hablar correctamente» - ars recte dicendi - Durante la Edad Media, sin embargo, el paso a una cultura que daba mayor importancia a la escritura, a lo que no sería ajena la expansión del cristianismo, que, al fin y al cabo, se basa en un libro, fue reduciendo gradualmente la retórica al estudio y clasificación de las figuras - es decir, al ornato del discurso - llegándose a su absoluto desprestigio a partir del Romanticismo tan pronto como se renunció al escolasticismo y se privilegió la originalidad en la expresión por encima de todo. De aquello nos ha quedado la idea de la retórica como sinónimo de discurso vacío y ampuloso y de un estudio que se resumía en aprender listas de figuras literarias de poca o ninguna utilidad.

Sin embargo, a mediados del siglo XX vuelve a aparecer el interés por la retórica entendida de nuevo como disciplina del discurso persuasivo - es el caso de Chaim Perelman - y, por lo tanto, como estudio de la expresión lingüística. La idea cala profundamente en teóricos de la literatura francófonos como Barthes, que parten de la lingüística y que vuelven a darle importancia a la retórica, replanteando su lugar en los estudios literarios (García Berrio, 1984, pág. 8). No es casualidad que Gérard Genette titulara sus primeros libros recopilatorios Figuras.

El planteamiento es bastante sencillo en teoría. Por lo general, la retórica como estudio de las figuras literarias se había considerado una parte de la poética, entendida como teoría de la literatura. Sin embargo, si pensamos en la retórica como estudio de la expresión lingüística y la poética como teoría de la expresión literaria, en realidad la poética tendría 
que integrarse en la retórica. Esa es la idea fundamental de esta nueva retórica que se contempla como estudio del discurso y de ahí que se haya criticado al Grupo $\mu$ el haber titulado Retórica general un libro que en realidad era un estudio de las figuras y, por lo tanto, solamente de una parte de ella: la elocutio (García Berrio, 1984, pág. 9).

En España se ha dedicado a la formulación teórica de esta nueva retórica sobre todo la línea de los profesores Antonio García Berrio, Tomás Albaladejo y Francisco Chico Rico, que a partir de la propuesta de García Berrio de la retórica como «ciencia de la expresividad» (García Berrio, 1984) ha hecho interesantísimas aportaciones, como la «retórica cultural» de Albaladejo, el concepto de «campo retórico» de Stefano Arduini (2000) - a quien también podemos incluir en este grupo - y, lo que más nos interesa aquí - la relación de la retórica con la traducción y la posición de esta última en un sistema retórico integral, tema sobre el que ha trabajado especialmente Chico Rico, tanto individualmente como en colaboración con Albaladejo.

\section{Retórica, neorretórica y traducción}

La traducción siempre ha sido la hija bastarda de los estudios literarios (Lefevere, 1995/1998). Especialmente desde que el Romanticismo empezara a valorar la originalidad como la base de lo artístico, las obras derivadas, como las traducciones, se convirtieron en un mal necesario pero despreciado. Sin embargo, no se puede decir que fuera nada nuevo, y basta con recordar las palabras de D. Quijote en su visita al impresor-traductor barcelonés (2a parte, capítulo LXII). La cita es de sobras conocida: D. Quijote considera la traducción un simple ejercicio de copia, a no ser que se traduzca del griego o del latín. En realidad, D. Quijote está expresando un prejuicio extendido en una sociedad en la que el conocimiento de lenguas se daba por supuesto en la gente educada. Solo determinadas lenguas, por supuesto, pero eso no impedía que verse obligado a leer traducciones fuera una muestra de ignorancia.

Se trata de un prejuicio de origen latino. Todo ciudadano romano que gozara de una educación como es debido sabía griego. ¿Para qué traducir, entonces? Sobre todo, por dos motivos: el primero tenía que ver con el sistema tradicional de enseñanza de lenguas, basado en la traducción'; el segundo, mucho más importante para nosotros,

1 En la novela de Ryotaro Shiba Las nubes sobre la colina (Zaragoza: Tres Hermanas, trad. de Yoko Ogihara y Fernando Cordobés) puede verse una descripción sobre cómo se enseñaba el chino clásico a los estudiantes japoneses siguiendo el sistema de traducción y cómo esa forma de enseñar la lengua contrasta con la del inglés, que empezó a extenderse en Japón a finales del siglo XIX. 
se refería al prestigio de la lengua propia siguiendo la idea de que si la lengua que hablamos es capaz de expresarse con tanta perfección como la que se toma por modelo, se la debe considerar a la misma altura. Esta visión positiva de la traducción, relacionada íntimamente con el concepto de la imitatio, es la que llevó a Boscán y a Garcilaso a imitar en castellano a los modelos italianos siguiendo el ejemplo de la tradición clásica, por mucho que para D. Quijote el toscano fuera una lengua «fácil». Según dice Chico Rico a partir de Lausberg:

En definitiva, para la teoría retórica latina, al traducir textos griegos al latín se ejercita y se afina el sentido lingüístico del idioma, ya que la extraordinaria riqueza temático-conceptual y expresivo-elocutiva del griego constituye un estímulo para la expresión latina. (La teoría de la traducción en la teoría retórica, 2002, pág. 28)

En el mismo artículo, Chico Rico explica cómo encajaba en el sistema latino el doble carácter de la traducción como actividad interpretativa del texto original y productora del texto traducido:

[...] si la teoría retórica consideró la traducción fundamentalmente como un ejercicio consistente en la composición o redacción de textos, la teoría gramatical la consideró sobre todo como un ejercicio consistente en el comentario de textos o crítica textual poetarum enarratio o enarratio auctorum. (2002, pág. 26)

Por desgracia, como ya hemos mencionado, el hecho de que las traducciones no sean obras originales ha supuesto que el estudio de la traducción como proceso sea totalmente ignorado por la crítica literaria y la teoría de la literatura, de forma que el estudio de los mecanismos de producción de textos artísticos nunca se ha preocupado por ella. Ciertamente, excepto casos extremos, como las traducciones a lenguas orientales de géneros occidentales (como ocurrió con la irrupción de la novela o el teatro en el sistema literario turco) o de la revolución italianizante en castellano, estamos hablando de lo mismo o casi. Es decir, no parece necesario que la poética le dedique una atención especial a la traducción de obras o géneros similares en lenguas que comparten la misma cultura y tradición literaria. Las traducciones al francés de la gran novela rusa —y de ahí a las demás lenguas europeas-, por muy interesante que pueda ser la cadena de transmisión, no supone un desafío del que tenga que ocuparse la teoría de 
la literatura. Por su parte, cuando se ocupa de traducciones, la literatura comparada suele dedicar su atención a las obras y no al proceso de traducción en sí.

Por lo que respecta a la otra cara de la moneda, a los estudios contemporáneos de traducción, tras unos inicios muy apegados a la lingüística — con bastante lógica一, parecen dividirse en dos grandes tendencias en relación con la traducción de literatura. Por un lado, están aquellos que, simplemente, la consideran una forma más de entre los distintos tipos de traducción existentes o que la despachan rápidamente aludiendo a su naturaleza más subjetiva. Por otro, se han realizado importantísimos estudios sobre las traducciones como parte del sistema literario de la lengua de llegada — pensemos, sobre todo, en los israelíes Even-Zohar y Toury-, pero, más que desde el punto de vista de la teoría literaria, desde el de los estudios culturales, lo que se llamó el «giro cultural» de los estudios de traducción. En estos últimos se han llevado a cabo interesantes estudios muy directamente relacionados con la poética y la literatura comparada, como los de André Lefevere y Susan Bassnett, pero habitualmente ninguno emplea la terminología ni las clasificaciones de la retórica tradicional, a pesar de haberse dedicado con profusión a las traducciones de la literatura clásica.

Algunos estudios con intención integradora han incluido, aunque sea parcialmente, aspectos que podríamos considerar pertenecientes al campo de la retórica. Por ejemplo, la «teoría general de la mediación interlingüe» de Sergio Viaggio (2004) —basada en el sistema teórico de Mariano García Landa - en su composición del «espacio perceptual hablístico intendido» incluye elementos que podrían clasificarse perfectamente dentro de las categorías clásicas de la retórica, desde la inventio hasta la actio, pasando, por supuesto, por la elocutio. Y las motivaciones y las intenciones pragmáticas del acto de habla podrían obviamente verse como parte de la intellectio.

Aunque este desencuentro entre los estudios retóricos y los de traducción y viceversa no parece tener mucha solución, en España se han realizado interesantes reflexiones que unen traducción y retórica, especialmente las de Albaladejo y Chico Rico, tanto juntos como por separado. Por una parte se descubre el lugar de la traducción dentro de los estudios retóricos clásicos - muy secundario, como hemos visto- (Chico Rico, 2002) y por otra se incorpora el sistema retórico al proceso de la traducción, como hace Chico Rico al proponer «la inserción de lo que llamaremos partes traductionis o traductoris officia en el tradicional sistema retórico de las partes artis u oratoris officia» (Retórica y traducción: Nónбıc у поínбıc en la traducción del texto literario, 2001, pág. 259). 
En cualquier caso, si la traducción es una operación lingüística, sus técnicas deberían poder someterse a las categorías de la retórica, entendida, de nuevo, como estudio integral del discurso. Sobre la traducción y, subrayando esto último, dice Arduini:

Traducir obliga a cuestionar [...] la relación significado-significante y, en consecuencia, la misma idea de signo, o distinciones como las de connotación y denotación. [...] la traducción presupone un modelo integrado en el que no quede excluido ninguno de los aspectos retóricotextuales. (Arduini, 2000, pág. 159)

Esta visión ofrece un interesante punto de vista en los estudios de traducción, pues la traducción como proceso puede pasar a estar bajo el paraguas de la retórica y, por lo tanto, ser estudiada usando las categorías clásicas. Es algo que ya hemos empezado a poner en práctica, aunque sea muy parcialmente, y que abre un interesante campo de estudio (Carpintero, 2017 y 2018).

\section{De las figuras retóricas a las técnicas de traducción: La Quadripartita ratio}

La base de los procesos retóricos consiste - ya venía a decirlo Aristóteles - en una desviación del lenguaje «normal», de lo que se ha llamado «el grado cero» de la lengua. Podemos discutir, y mucho, las mismas nociones de «desvío»² y de "grado cero» (Grupo $\mu, 1970$, págs. 86-89 y 77-82), pero no por ello dejan de ser comprensibles y útiles. Los procedimientos retóricos clásicos para estos desvíos se resumían en cuatro, la quadripartita ratio de Quintiliano. Esta quadripartita ratio eran las cuatro operaciones básicas en las que se basan las figuras retóricas —véase, sin ir más lejos, la clasificación que hace el Grupo $\mu$ (Retórica general, 1970, págs. 91-95)—: (a) adiectio: adición o añadido de algún elemento o componente; (b) detractio: sustracción u omisión de algo; (c) transmutatio: trasposición, cambio de un elemento por otro, que el Grupo $\mu$ consideró como un caso de omisión y posterior adición; y (d) immutatio, la permutación de elementos entre sí, particularmente el intercambio de posición.

Estas cuatro operaciones, aplicadas a los distintos niveles lingüísticos, desde el fonético al textual-pragmático crean un cuadro en el que podemos incluir cómodamente

2 La idea de desvío («swift») ha sido muy utilizada en los estudios de traducción, bien al considerar el texto traducido un desvío del texto original —lo que, sin duda, es-, o, como hace Kitty van-Leuven Zwart, tomando ambos textos como desvíos de un hipotético texto ideal que sirva como tertium comparationis, lo que llama «architransemas» (Leuven-Zwart, 1989, págs. 155-170). 
todas las figuras. Clasificaciones más tradicionales - como la separación entre tropos y figuras, o entre figuras de dicción y de pensamiento- resultan demasiado vagas para nuestro objetivo, o bien parecen mezclar categorías - cuando se distingue entre figuras según el procedimiento (por ejemplo, por repetición o supresión) y figuras lógicas-.

Una vaguedad similar en la clasificación de los procedimientos parece haber sido habitual en los estudios de traducción. La «desviación» del grado cero, es decir, del texto original, ha sido analizada en sus posibles variedades pero no parece haberse hecho con ánimo clasificatorio sino, más bien, enciclopédico, como listas de procedimientos técnicos o, sencillamente, técnicas de traducción.

Sin embargo, las dieciocho técnicas de traducción que enumera Amparo Hurtado Albir (2001, págs. 256-271), basándose en el trabajo pionero de Vinay y Dalbernet, pueden reducirse a esas cuatro operaciones de la quadripartita ratio, siempre y cuando tengamos en cuenta que podemos hacerlo en todos los niveles lingüísticos, desde el fonético hasta el textual y el pragmático, pasando por el morfosintáctico. Sin olvidar el plano denotativo ni el connotativo, tanto en el análisis previo a la traducción del texto original como en la traducción entendida como texto perteneciente a la lengua y a la literatura de llegada. Ni todos los sonidos ni todas las imágenes despiertan las mismas asociaciones en todas las lenguas y no solo hay que preocuparse por buscar el equivalente más preciso, sino también por las sugerencias que se pueden despertar en la cultura de llegada.

Una vez que asumimos que podemos aplicar las operaciones de la quadripartita ratio en todos los niveles lingüísticos tanto en el plano creador de la traducción como operación generadora de un texto nuevo en la lengua de llegada, como en el plano crítico y más pasivo del análisis de la traducción como producto de dicho proceso, veremos que podemos aplicar estas operaciones básicas también —ahora desde un punto de vista retórico- a las tres grandes «operaciones constituyentes de discurso»: la inventio, la dispositio y la elocutio. Asimismo conviene no olvidar una parte de la retórica tradicionalmente muy poco tratada por los autores clásicos, pero que está siendo reivindicada por la neorretórica: la intellectio (Chico Rico, 1995/1998, págs. 493494). 


\section{Intellectio e inventio}

\section{a. La intellectio como operación previa al discurso}

La intellectio es en principio la comprensión del contexto pragmático por parte del orador (Chico Rico, 1995/1998, pág. 495), tanto desde el punto de vista del tema (el campo), como de la forma de transmisión (el modo), como de las relaciones entre el emisor y el receptor o receptores (el tenor). Sin embargo, también se está entendiendo últimamente como una operación creadora de los parámetros del universo discursivo, universo del que se extraerán los «lugares» de la inventio. Como dice Chico Rico:

La intellectio consiste en el examen minucioso de la realidad extensional [es decir, exterior al texto, RC] sobre la que la inventio va a operar encontrando o hallando las ideas o elementos semántico-extensionales necesarios para la constitución de una estructura de conjunto referencial concreta e intensionalizándolos 3 . (Chico Rico, 1989, pág. 50)

Definición que luego ampliará incluyendo categorías decididamente pragmáticas:

[...] ha sido descrita y explicada como una operación retórica instructiva que da como resultado no un nivel constructivo en la construcción retórica, sino un nivel instructivo situado en la organización del hecho retórico, que abarca tanto el discurso retórico como las relaciones que dicho discurso mantiene con el orador, el público, el referente y el contexto en el que tiene lugar la comunicación. (Chico Rico, 1995/1998, pág. 495)

La intellectio es, en suma, una operación previa que permite al orador $-\mathrm{y}$ al traductor, tanto en su faceta de analista del texto original como de creador del texto metaconstruir los parámetros en que se va a desarrollar la comunicación, el «campo retórico» del que habla Arduini, tan próximo, mutatis mutandis, al «espacio hablístico» de GarcíaLanda y Viaggio (Viaggio, 2004, págs. 24-31).

3 Sobre este término dice en nota Chico Rico: «Ha sido el profesor Albaladejo quien por primera vez ha utilizado el término intensionalización [...] para referirse al proceso de formalización lingüística de la realidad». 
Gracias a la intellectio el orador puede establecer el campo retórico, que, como horizonte comunicativo-cultural del discurso (Arduini, 1991), hace posible la comunicación retórica. (Albaladejo \& Chico Rico, 1998, pág. 341)

Todo esto refuerza nuestra idea de que las grandes categorías de la retórica clásica son perfectamente aplicables a la traducción

\section{b. La inventio como enciclopedia de lugares comunes}

Como hemos visto, la inventio es una operación constituyente de discurso porque opera directamente sobre él y no sobre la realidad externa, dominio de la intellectio. Y su función, por así decirlo, consiste en encontrar los temas concretos y la forma de desarrollarlos que se va a realizar en el texto. Para ello, los clásicos tenían a su disposición un repertorio de temas y subtemas, los «lugares» —-topoi o loci-, que permitían «encontrar» formas concretas para desarrollar las ideas que se pretendían exponer.

Su finalidad [de la inventio, RC] es establecer los contenidos del discurso. El término contenido, en este contexto, debe entenderse en un sentido diferente a asunto: un discurso versa sobre un determinado tema o asunto que, en su interior, está constituido por una serie de contenidos o ideas específicas. [...] invenire es buscar en la memoria, que es concebida como un conjunto dividido en topoi o loci (tópicos o «lugares») en donde se encuentran las ideas susceptibles de aplicación.

El lugar retórico (topos o locus) es, pues, una casilla perfectamente ordenada en un sistema de contenidos aplicables al discurso. (Azaustre \& Casas, 1997, pág. 23)

Por otra parte, estos «lugares» podían llegar a ser bastante rígidos; no tenemos más que pensar en ejemplos como el del carpe diem o el del beatus ille, que implicaban el uso de formas muy concretas. Por ejemplo, en el caso del carpe diem, la descripción de una muchacha - descriptio puellae - aunque la conveniencia de aprovechar el tiempo también fuera aplicable a los varones. Pero no solo eso, sino que también la imagen de la muchacha es muy concreta, siempre rubia, de piel blanca; seleccionando elementos muy concretos - el pelo, el cutis - y describiéndolos habitualmente de arriba abajo. 
Todos estos condicionamientos y el propio tema implican también una ubicación muy concreta de la voz poética, la de un hombre mayor que la muchacha en cuestión, lo suficiente como para aconsejarla, algo que podríamos relacionar con la intellectio como localización consciente del autor previa al discurso (Chico Rico, 1995/1998, págs. 494495).

Estos lugares comunes se relacionan muy directamente con la tradición cultural, por lo que pueden variar de una cultura y de una época a otra. André Lefevere expuso muy claramente las dificultades de comprensión y asimilación, y, por lo tanto, de traducción, de las casidas árabes clásicas a las lenguas europeas occidentales modernas con respecto a lo que él llama «universo del discurso» y que nosotros podemos asimilar sin dificultad a la inventio, pero también los que planteaba y plantea traducir al mismísimo Homero (Traducción, reescritura y la manipulación del canon literario, 1992, págs. 95124). A ello habría que añadir la importancia que determinados lugares poseen dentro de la obra literaria de cada autor, creando un «universo del discurso» particular según la enciclopedia cultural de cada uno.

\section{c. El traductor como lector y como productor}

Parece casi innecesario recordar que el traductor es lector de la obra original y productor de la obra traducida. Sin embargo, el traductor no es ni un lector ni un productor/escritor «normal». Si todo traductor requiere una alta competencia lingüística pasiva en la lengua original y activa en la lengua de llegada, en el caso de una obra literaria necesita asimismo una buena competencia literaria e, igualmente, una competencia técnica «en cuanto al análisis y estudio de la obra literaria» (Chico Rico, 2001, págs. 265-267). Es decir, aparte de ser capaz de comprender y reexpresar el texto (proceso ya estudiado en su momento por Eugene Nida), necesita (a) poseer las herramientas y la capacidad técnica que le permitan analizar los formantes de la obra literaria de forma que pueda ser capaz de reproducirlos y (b) ser capaz de hacerlo con la sensibilidad estético-literaria suficiente como para permitir que la traducción pueda ser considerada una obra literaria en sí misma. Hasta cierto punto, esto cubre la faceta racional — la competencia técnica — y la intuitiva — la competencia estético-literariade una buena traducción. Por mucho que se repita hasta la saciedad cuánto se pierde al traducir, es innegable que si la obra traducida careciera por completo de cualidades artísticas, sería imposible que pudiera ejercer su influencia en la cultura de llegada por muy notable que fuera el original. 
Entre el proceso de producción/escritura del texto original y el traducido existe una diferencia fundamental, y no solo porque estén escritos en lenguas distintas:

[...] la diferencia esencial existente entre los procesos de la producción literaria y los procesos de la traducción literaria radica en la diferencia esencial entre el dominio referencial de aquéllos y el dominio referencial de éstos: mientras que el dominio referencial de los procesos de la producción literaria lo constituye el mundo, el dominio referencial de los procesos de traducción literaria lo constituye la obra de arte verbal original, entendida como construcción estructural, como construcción de significado poético y como construcción pragmática. (Chico Rico, 2001, pág. 267)

La competencia técnica del traductor le permitirá analizar en profundidad los entresijos de esa construcción tripartita que es la obra literaria - original - y recrearla en la lengua de llegada. La traducción se constituye, por decirlo así, en una creación "guiada». Pero si los aspectos estructurales, estéticos y quizá incluso pragmáticos pueden ser compartidos por los lectores de las dos lenguas implicadas, no ocurre lo mismo con esos «dominios referenciales». Es decir, mientras que un lector francés y otro español, por ejemplo, pueden compartir gustos y estética, no necesariamente comparten las referencias culturales.

Es de sobra conocida la anécdota de cuando Ulysses S. Grant visitó Japón tras dejar la presidencia y le ofrecieron un espectáculo de teatro tradicional noh que le causó una profunda impresión. En casos similares existen grandes diferencias tanto estéticas como referenciales entre la cultura que ha generado la obra y el receptor de una cultura y una lengua distintas. Evidentemente, no ocurriría lo mismo con un español que acudiera a una obra de teatro en Francia. Sin embargo, aunque franceses y españoles lo compartamos casi todo desde el punto de vista cultural y literario, las dificultades de traducción que plantean algunos tipos de textos dejan bien claras las diferencias entre nuestros referentes. Si pensamos en obras humorísticas como Astérix - sobre cuyas traducciones se ha escrito bastante - nos encontraremos no solo con la necesidad de alterar referencias culturales que no serían reconocidas en la lengua de llegada (Hurtado Albir, 2001, págs. 33-36), sino también con formas distintas de entender lo humorístico.

Si pensamos en esta posición única de la traducción en términos de la retórica clásica, nos daremos cuenta de que gran parte de la competencia pragmática necesaria 
- incluyendo esas formas de entender el humor - puede ser considerada dentro de la intellectio. Es lo que Chico Rico ha llamado la intellectio traductoris:

La recepción o interpretación de la obra de arte verbal original por parte del traductor literario, pues, es una actividad necesariamente previa a la de producción o construcción de la obra de arte verbal terminal y forma parte de las funciones esenciales de las operaciones noéticas - intellectio - que aquél [el traductor] debe llevar a cabo. ${ }^{4}$ (Chico Rico, 2001, pág. 274)

Por su parte, pertenecería al dominio de la inventio la «di-visión» del mundo; es decir, tanto su percepción como su parcelación en categorías que permitan la mejor aprehensión y comprensión de sus realidades. Dicha parcelación está determinada por la cultura y, por lo tanto, existirán diferencias en mayor o menor grado según la distancia cultural de los textos implicados en la traducción, tanto desde el punto de vista sincrónico-geográfico como diacrónico.

En este punto es conveniente abrir un breve paréntesis. Cuando se teoriza sobre la traducción, incluso cuando se teoriza sobre la lectura en general, da la impresión de que se asume que el traductor - o el lector - es capaz de entender de una manera absoluta el texto y todas sus implicaciones. Y, en el caso del traductor, de reexpresarlo además en una lengua que puede que sea multicultural. No obstante, la realidad es bastante distinta y nunca uniforme. Ni el mejor de los traductores es capaz de introducirse en la mente del autor original de manera perfecta, ni suele ser posible traducir un texto con todas sus connotaciones.

Por otra parte, el traductor no solo se expresa en su particular idiolecto, sino que también tiene un trasfondo personal, así como unas actitudes propias, que coincidirán más o menos con el autor del texto original. Por supuesto, el buen traductor será

4 Chico Rico separa las operaciones retóricas en tres bloques: (1) operaciones noéticas, la intellectio; (2) operaciones poiéticas, el trío inventio, dispositio y elocutio; y (3) operaciones prácticas, la memoria y la actio/ pronuntiatio. Solo las tres centrales son operaciones estrictamente textuales. En lo que se refiere a la traducción, dentro de la intellectio, y siempre siguiendo a Albaladejo, considera «las relaciones que dicha obra mantiene con todos y cada uno de los componentes que la hacen posible» y que son (1) «el contexto comunicativo general» del original; (2) «la voluntad comunicativa y artística del autor» del original, «relacionada con su voluntad de género»; (3) relación (pragmática) entre autor y receptores de la obra original; (4) «la tradición literaria, que funciona como contexto textual de la obra de arte verbal original»; (5) «la tradición traductológica definida por las posibles traducciones existentes» y podríamos añadir que también definida por las normas iniciales y preliminares de Toury; (6) «el universo cultural [...] en el que teóricamente se ubica la obra de arte verbal original». (Chico Rico, 2001, págs. 276-277) 
consciente de todo ello - es lo que en otro lugar llamé la «localización del traductor» (Carpintero, 2013)—, pero eso no implica que pueda evitar dichas diferencias para anularlas. Todo ello, no cabe duda, repercutirá en la traducción, tanto desde el punto de vista de la elocutio, en cuanto a esa «localización» del autor y del traductor, como de la inventio, en lo que se refiere a las diferencias en las categorías culturales de percepción del mundo.

En lo que respecta a la inventio traductoris, Chico Rico (a partir de Albaladejo) la relaciona con la «elaboración» en la obra traducida de un modelo de mundo y un «conjunto referencial o referente» a partir de lo «obtenido» por el traductor en la obra original. Como hemos visto, la diferencia entre el autor original y el traductor consiste en que este último no crea a partir de la nada, sino que tiene la obra original siempre como pauta (Chico Rico, 2001, págs. 277-278). Sin embargo, y a pesar de que se siga la guía permanente del original, no hay que olvidar las diferencias culturales o lingüísticas que pueden obligar a crear un «conjunto referencial» bastante distinto. Pensemos, por ejemplo, en las diferencias, inexistentes en español, entre «pig»y «pork» 0 «can» $y$ «may», que, manteniéndose en el nivel léxico, corresponden a estructuras referenciales diferentes que generan distintos loci. También podemos encontrar otras más sutiles y complejas, como las que hay entre el sistema español de pasados verbales y el turco; mientras que el español se basa en la diferencia aspectual perfectivo/imperfectivo («vino»/«venía»), en turco la distinción se hace entre observación directa e inferencia («geldi»/«gelmiş»). En este tipo de casos casi mejor sería hablar de distintas concepciones del mundo, ya que no es «cortar» en distintas porciones una misma realidad, sino que hablamos de percepciones completamente diferentes. Obviamente, todo esto plantea problemas de traducción que pueden ser bastante serios.

\section{Ejemplo de problemas de traducción al nivel de la inventio: Traducción al castellano de algunos poemas de Ataol Behramoğlu}

Por circunstancias que no vienen al caso, durante el último trimestre del pasado año 2019 tuve la oportunidad de traducir algunos poemas del conocido poeta, traductor y académico turco Ataol Behramoğlu, parte de los cuales ya contaban una traducción al español, algunos del inglés y otros del francés. Analizando las traducciones existentes, así como las francesas y norteamericanas de las que partían, es posible percibir diferencias considerables con el original que no solo se encuentran en el plano de la expresión, sino que se deben también a la consideración de los temas (a la inventio, por lo tanto). 
Podemos ver un primer ejemplo en el poema «Alanya Günlükleri» («Diario de Alanya»), traducido de la versión francesa de Aytekin Karaçoban ${ }^{5}$. Vamos a dejar de lado que el título se tradujera al español como «Revista de Alanya» porque fue un error inducido por la ambigüedad del título francés, "Journal d'Alanya». Hay, sin embargo, un par de detalles que llaman la atención desde el punto de vista de los topoi, es decir, de los tópicos o temas, y que entran de lleno en el campo de la inventio. ${ }^{6}$

El primer detalle relativo a la inventio lo encontramos en la primera parte del poema. Se trata de una imagen de «ella», de la mujer, que aparece en el primer verso de tres de las cuatro estrofas. Como ejemplo nos sirve perfectamente la primera:

Bir bereket tanrıçası gibi geldin kadınım

Sepetinde peynir, ekmek ve suyla

Akdeniz gibi çırpınıyordu eteklerin

Gözlerinde tuz ve mavilikler

Que, siguiendo casi literalmente a la versión francesa, se traduce al español como:

Tú viniste como una diosa de la fertilidad

Con el queso, el pan y el agua en tu cesta

La sal y el azul en tus ojos

tu falda se agita como el Mediterráneo ${ }^{7}$

Podríamos analizar varios aspectos de la traducción, como el uso de «tú» en lugar del vocativo «mujer (mía)» («kadınım») del original turco; el empleo de artículos determinados en el segundo verso (¿por qué «el» queso?) o, lo más llamativo, el cambio de orden entre el tercer y el cuarto versos; todo ello atribuible a la versión francesa.

Sin embargo, nos limitaremos a lo que afecta estrictamente a la inventio, y que está relacionado con el otro ejemplo que veremos después, la traducción de «bereket

5 A la que se puede acceder en la página web del autor: http://www.ataolbehramoglu.com.tr/sayfa. aspx?id=Poesie

6 Conviene advertir también que, al menos en nuestra opinión, la expositio —entendida como forma de la expresión- de la traducción francesa es excesivamente «literaria», pero esa es una cuestión que se debería tratar en otro lugar.

7 En la página web del Festival Internacional de Poesía de Medellín —-de donde he tomado la traducciónno queda muy claro quién es el traductor, aunque según comunicación personal del señor Behramoğlu se trata de Sergio Badilla. Vid. https://www.festivaldepoesiademedellin.org/es/Revista/ultimas_ediciones/88_89/ behramoglu.html 
tanrıçası» como «diosa de la fertilidad». Sin duda, una de las posibles acepciones de «bereket» es «fertilidad», como demuestra el título de una famosa obra de Orhan Kemal, Bereketli Topraklar Üzerinde (Sobre tierras fértiles). Nuestro diccionario académico relaciona la fertilidad con la abundancia si se refiere a la tierra: «Dicho especialmente de la tierra: Que produce mucho». En nuestro ejemplo «bereket» está condicionado por la palabra «diosa» con la que forma una unidad: la mujer del poema se compara a una diosa de esa «bereket», traducida al francés como «fertilité».

Lo cierto es que el término «fertilidad» asociado a la mujer y no a la tierra suele relacionarse más con la segunda acepción de «fértil» del diccionario: «Dicho de un ser vivo: Capaz de reproducirse». Así pues, con el uso de «fertilidad» estaríamos vinculando - como se hará luego en otra parte del poema original - lo femenino con la reproducción. Hasta ahora, nada que objetar.

No obstante, esta interpretación parece contradecirse con la clave que nos propone el siguiente verso. El pan, el queso y el agua que trae la mujer en la cesta no tienen mucha relación con su capacidad reproductiva. Así pues, tendríamos que acudir al otro campo semántico de la palabra «bereket», no el de la fertilidad, sino el de la abundancia. De hecho, el famoso «cuerno de la abundancia», en turco es «bereket boynuzu», lo que se relaciona mucho mejor con el contenido, modesto pero abundante, de la cesta de la mujer del poema. La conclusión a la que se puede llegar es que la traducción de «bereket» por «fecundidad» parece haber sido producto de una cierta visión de «lo femenino» (la isotopía dominante en el poema) y no de acuerdo con la imaginería habitual de la «abundancia». Por supuesto, en turco pueden permitirse el combinar ambas interpretaciones, pero en español (y en francés) tendríamos que atender a las «valencias» (Jones, 1989) de cada uno de los términos. En este ejemplo, parece pesar más la idea de la abundancia (de queso, pan y agua) que la de la fertilidad de la tierra o de la mujer. ${ }^{8}$

8 Es conveniente recordar lo que decía Jakobson sobre la función poética: «The poetic function projects the principle of equivalence from the axis of selection into the axis of combination» (1958, pág. 358). Dicho de otra manera, tenemos que interpretar los términos clave —especialmente si pensamos traducirlos- en cuanto a su capacidad combinatoria con el resto de los elementos que forman el poema. Volvemos así a la idea de las «valencias» de Jones y a la lectura tabular que propone el Grupo $\mu$ : «Ce type de lecture [la «lectura tabular»], que nous tenons pour un modèle fondamental de notre culture littéraire, est le produit de la reconnaissance de plusieurs isotopies et des réévaluations qui autorisent le passage de l'une à l'autre. Le lecteur de poèmes est donc celui qui peut parcourir le texte suivant plusieurs plans de déchiffrement, parcours qui lui permet, soit dans la relecture, soit à la faveur de réévaluations rétrospectives [...], d'enrichir sans cesse les cases du tableau». (Rhétorique de la poésie. Lecture linéaire, lecture tabulaire, 1977, pág. 196) 
En la quinta parte del poema encontramos otro caso interesante que fácilmente podemos relacionar con la inventio y que también es curioso desde el punto de vista de la elocutio. En esta parte el poeta se muestra en desacuerdo con la comparación tópica entre el mar y la mujer (o viceversa) ya que ve en la agresividad del mar un carácter masculino. Dicho a la manera de Francis R. Jones, en las «valencias» del concepto de «mar», para Behramoğlu pesan más aspectos tradicionalmente masculinos como la agresividad que otros que se han querido identificar con la mujer como la voluptuosidad de las curvas de las olas, la profundidad o la infinitud, o, pasando al extremo negativo, la volubilidad de las mareas.

Para el poeta lo verdaderamente femenino es la tierra, y aquí ahora sí que podríamos pensar en la «fertilidad», pero, por desgracia, no se la menciona expresamente en esta parte del poema. La estrofa en que compara la tierra con la mujer es la siguiente:

\author{
Topraktır \\ Dişi olan; \\ Bir rahim gibi \\ Güçlü, kıpırtısız \\ Doyumsuz \\ Beklemede...
}

En español, que de nuevo sigue fielmente al francés:

\author{
Es la tierra \\ Quien es mujer \\ Fuerte como un útero, \\ Inmóvil \\ Insatisfecho \\ A la espera de...
}

Lo que más llama la atención de la traducción es la palabra «útero», que parece rotundamente poco poética. En español resulta excesivamente médica y anatómica si la comparamos con la palabra turca «rahim», mucho más familiar y neutra. En realidad, la extrañeza proviene del campo de la inventio de nuevo. Con «bereket» hemos visto que la traductora al francés parecía identificar lo femenino con la reproducción; pues bien, ahora el poeta lo hace con toda claridad. ¿Cuál es, pues, el órgano o la parte del 
cuerpo que en español relacionamos directamente con la reproducción desde un punto de vista más literario y menos anatómico? Vamos a emplear para ello unos ejemplos bien conocidos. Pensemos que para la concepción de Mahoma en la noche de Regaip en turco se usa la expresión «rahme düştü», «cayó en la matriz (de su madre)», usando el mismo término del poema («rahim»). Pensemos también que en la Salve se le dice a la Virgen María que Jesucristo es: fructum ventris tui, «fruto de tu vientre». Simplemente con este ejemplo religioso podemos concluir que lo que en español relacionamos directamente con la femineidad fértil/reproductora es el vientre, no el útero. Es así como cabe entender el famoso poema de Miguel Hernández «Menos tu vientre, / todo es confuso. / Menos tu vientre, / todo es futuro / fugaz, pasado / baldío, turbio...». Queda, por supuesto, el problema de que tampoco es muy aceptable (vid. Gideon Toury) el verso «fuerte como un vientre», pero eso habría que discutirlo en otro lugar.

La relación con la inventio de este debate mínimo «útero/vientre» radica en dos puntos. Por una parte, la consideración de lo poético y lo no poético basada en las connotaciones de «rahim/útero» - es decir, qué términos son aceptables como «poéticos» y cuáles no-. Por otra, nos encontramos con el campo semántico de la fecundidad/maternidad y los respectivos «dominios referenciales» en cada lengua. Dicho de otra forma, qué órgano identifica cada lengua con la maternidad. El original nos presenta un término bastante neutro, mientras que las posibles soluciones en español son, o bien excesivamente anatómicas («útero»), o bien demasiado amplias («vientre») para este poema concreto?.

Pasemos ahora a un ejemplo de otro poema y a otro campo semántico. Behramoğlu tiene un (famosísimo) poema titulado «Bir Gün, Mutlaka». Se trata de un poema muy militante, acorde con su ideología socialista, en el que se augura la victoria final «un día» («bir gün»), victoria que se da por segura («mutlaka»). Así pues, una traducción perfectamente literal del título sería: «un día, seguro», o quizá «algún día, seguro» ${ }^{10}$. Lo que llama la atención de inmediato en la traducción española (de Sergio Badilla, muy probablemente a partir de la traducción al inglés de Walter $\mathrm{G}$. Andrews, más que de la francesa de Y. Avanç) es que el título «Un día, seguramente», convierte la certeza en probabilidad.

9 Con lo que quizá cabría la posibilidad de especificarlo con un adjetivo: «fuerte como un vientre femenino».

10 Al autor le habría gustado conservar la aliteración en «a» de la palabra «mutlaka» al traducir al español, según una comunicación personal, pero no parece muy factible, además de que según el sistema de «valencias» de Jones tendría un valor bastante bajo. Es decir, en español no sería una aliteración significativa y es preferible mantener una palabra «redonda» como «seguro» teniendo en cuenta el carácter militante del poema. 
Esta traducción del «surely» del título inglés no podemos interpretarla como una desviación al simple nivel de la palabra, sino que procede de algo más amplio. Una visión militante de la vida —y de la poesía - implica necesariamente la seguridad absoluta en la victoria futura. Dentro de esa concepción militante y convencida es como parecen preferibles términos como «manifestación» mejor que «marcha» (por «yürüyüş») ${ }^{11}$, al menos en castellano de España y como sí hace Y. Avunç en francés.

De igual manera, parece necesaria la repetición constante del verbo «vencer» en la última parte del poema. En ese sentido, son clave los versos:

Uyanıyorum ağlayarak, bir gün mutlaka yeneceğiz!

Bir gün mutlaka yeneceğiz, ey ithalatçılar, ihracatçılar, ey şeyhülislam!

Bir gün mutlaka yeneceğiz! Bir gün mutlaka yeneceğiz! Bunu söyleyeceğiz bin defa!

Sonra bin defa daha, sonra bin defa daha, çoğaltacağız marşlarla

Que en inglés Andrews traduce así:

I wake up crying, one day surely we must win

One day surely we will defeat you, oh you importers, exporters, oh you great cleric of Islam

One day surely we'll defeat you, one day surely we'll defeat you, we'll say it a thousand times

Then a thousand times more, then a thousand times more, we'll multiply it with marching songs

Y Badilla:

Me despierto llorando, sin duda un día tenemos que ganar Un día, sin duda le derrota [i-remos?] ${ }^{12}$, ah importadores, exportadores, ah gran clérigo del Islam

Un día, seguramente te venceremos, un día sin duda te derrotaremos lo diremos una y mil veces

11 Entre otras cosas porque «marcha» aparece con dos significados distintos en turco, como «marcha de protesta» («yürüyüşs) y como «himno» («marş»).

12 En el texto que aparece en la página web del festival de Medellín aquí hay claramente una errata. 
En seguida, una y mil veces más, luego mil veces más, vamos a multiplicar las marchas con canciones

Dejemos de lado, ya que por el momento no nos interesan, interpretaciones discutibles en la traducción del inglés al español, como la de «we'll multiply it with marching songs» («çoğaltacağız marşlarla») por «vamos a multiplicar las marchas con canciones». Lo que sí nos interesa por ser evidente en el original es la repetición de «yeneceğiz» (cuatro veces en tres versos) y «bin defa» (tres veces en dos versos). Andrews, por alguna extraña razón, traduce «yeneceğiz» primero por «we must win» y después por «we will defeat you». Badilla le da una mayor variación aún: «tenemos que ganar», «le [-s] derrota [-remos]», «te venceremos», «te derrotaremos». Esta variedad corresponde, sin duda, a la resistencia a repetirse en pocas líneas típica del inglés y del español (y no tanto del turco). Pero debemos tener muy presente que inmediatamente después el poeta dice expresamente que va a repetir ese grito «mil veces, luego mil veces más, luego mil veces más...». Es decir, se trata en este caso de una repetición necesaria si atendemos al resto del texto.

Esta diversidad terminológica acaba afectando directamente al plano de la inventio. ¿Por qué? Porque cualquiera que tenga un ligero conocimiento de los movimientos de izquierda sabe que el verbo que se usa no es «derrotar» ni «ganar», sino «vencer». $Y$ no «vencer a alguien», sino simplemente "vencer», en un uso intransitivo ${ }^{13}$ : «venceremos». Así era como se llamaba el himno del bloque de Unidad Popular de Allende en Chile, que ha sido objeto de múltiples versiones, incluida una en Turquía por parte del Grup Yorum, precisamente con el título «Venseremos» [sic].

Todo esto no debe tomarse como una crítica a las traducciones mencionadas, sino como indicación de cómo un punto de vista previo sobre determinados temas - casi un pre-juicio - puede afectar al resultado final. Posiblemente, en el ejemplo que nos ocupa habría sido necesaria una visión del mundo más militante y ortodoxa en lugar de una más «literaria». Esta postura abiertamente política —algo que entra de lleno en el terreno de la intellectio - habría permitido la adopción de las claves lingüísticas adecuadas al traducir; es decir, habría podido conducir a los traductores a los loci de la inventio más apropiados. En ese sentido, quizá habría sido más fiel traducir «yeneceğiz» al inglés por «we shall overcome», el himno de la época de las manifestaciones por los derechos civiles en EE.UU., aunque, siendo norteamericano

13 Ese es el gran problema del verbo «derrotar», que desvía la atención hacia el objeto directo. 
el propio Walter G. Andrews, quizá fuera para él una expresión excesivamente marcada por una época determinada.

En suma, aunque generalmente las diferencias entre original y traducción suelen analizarse casi exclusivamente en el plano léxico-gramatical, hay casos en los que reflejan no solo concepciones distintas del mundo entre una lengua y otra, sino también la forma en que dichas lenguas y las culturas de las que son medio de expresión dividen y marcan sus percepciones. Estos últimos planos, no estrictamente lingüísticos, son los que la retórica clásica veía como dominios de la intellectio y la inventio respectivamente. Por usar el último de nuestros ejemplos, una postura ideológica concreta - analizable desde la intellectio - puede conducirnos a una demarcación más precisa de los campos semánticos correspondientes desde el punto de vista de la inventio y, por consiguiente, a una elección léxica más adecuada (de nuevo Toury).

\section{Sistema de evaluación: Por pares externos.}

Conflicto de intereses: El autor declara no tener ningún conflicto de intereses.

Apoyo económico: El autor declara que no ha recibido ningún apoyo económico para este trabajo.

Peer-review: Externally peer-reviewed.

Conflict of Interest: The author has no conflict of interest to declare.

Grant Support: The author declared that this study has received no financial support.

\section{Bibliografía}

Albaladejo, T. \& Chico Rico, F. (1998). La "intellectio" en la serie de las operaciones retóricas no constituyentes de discurso. Teoría/Crítica (5), 339-352.

Arduini, S. (2000). Prolegómenos a una teoría general de las figuras. Murcia: Universidad de Murcia, Servicio de Publicaciones.

Azaustre, A. \& Casas, J. (1997). Manual de retórica española. Barcelona: Ariel. Nueva edición, 2015.

Carpintero, R. (2013). La "Iocalización" del traductor. en AA. VV.: Hijos de Babel. Reflexiones sobre el oficio de traductor en el siglo XXI (pp. 85-92). Madrid: Fórcola.

Carpintero, R. (2017). Back to Basics: Transfer as a Metaphorical Process. Litera: Dil, Edebiyat ve Kültür Araştırmaları Dergisi, $27(1), 1-21$.

Carpintero, R. (2018). Dispositio y compositio en la traducción de poesía turco-español. Trans. Revista de Traductología, 22, 99-114.

Chico Rico, F. (1989). La intellectio. Notas sobre una sexta operación retórica. Castilla, Estudios de Literatura (14), 47-55. 
Chico Rico, F. (1995/1998). La intellectio en la Institutio Oratoria de Quintiliano: ingenium, iudicium, consilium y partes artis. En T. Albaladejo, E. Río y J. Caballero (eds.), Quintiliano, historia y actualidad de la retórica : actas del Congreso Internacional (pp. 493-502). Madrid y Calahorra, 14 al 18 de noviembre de 1995: Logroño : Instituto de Estudios Riojanos; Calahorra : Ayuntamiento de Calahorra, 1998.

Chico Rico, F. (2001). Retórica y traducción: Nónбıc y пoínбıç en la traducción del texto literario. En P. Y. Raccah y B. Saiz Noeda (eds.), Lenguas, literatura y traducción. Aproximaciones teóricas (pp. 257-285). Madrid: Arrecife.

Chico Rico, F. (2002). La teoría de la traducción en la teoría retórica. Logo. Revista de Retórica y Teoría de la Comunicación (3), 25-40.

García Berrio, A. (1984). Retórica como ciencia de la expresividad (Presupuestos para una retórica general). E.L.U.A. Estudios de Lingüística Universidad de Alicante (2), 7-59.

Groupe $\mu$. (1977). Rhétorique de la poésie. Lecture linéaire, lecture tabulaire. Paris: Éditions du Seuil, 1990.

Grupo $\mu$. (1970). Retórica general. (J. Victorio, trad.) Barcelona: Paidós, 1987 (edición española revisada). Hurtado Albir, A. (2001). Traducción y traductología. Introducción a la traductología. Madrid: Cátedra.

Jakobson, R. (1958). Linguistics and Poetics. En T. Sebeok (ed.), Style in Language (pp. 350-377). Cambridge, Mass.: Technology Press of Massachusetts Institute of Technology ; London : John Wiley \& Sons 1960. Jones, F. (1989). On Aboriginal Sufferance: A Process Model of Poetic Translating. Target, 1 (2), 183-199. Lefevere, A. (1992). Traducción, reescritura y la manipulación del canon literario. (M. Vidal y R. Álvarez, trads.) Salamanca: Colegio de España (1997).

Lefevere, A. (1995/1998). La literatura comparada y la traducción. En M. J. Vega, y N. Carbonell , La literatura comparada: Principios y métodos (pp. 206-214). Madrid: Gredos.

Leuven-Zwart, K. M. (1989). Translation and Original. Similarities and Dissimilarities I. Target (1), 151-181.

Viaggio, S. (2004). Teoría General de la mediación interlingüe. Alicante: Servicio de Publicaciones de la Universidad de Alicante. 
